Poster sessions

Abstract P205 Table 1 Crude admission rates, Poisson regression modelling of admissions, mortality and median ICU length of stay in people with Bronchiectasis and Chronic Obstructive Pulmonary Disease (COPD)

\begin{tabular}{|c|c|c|c|c|c|c|}
\hline Bronchiectasis & Number of admissions & Person years & $\begin{array}{l}\text { Crude admission rate per } \\
100,000 \text { person years }(95 \% \mathrm{Cl})\end{array}$ & $\begin{array}{l}\text { Crude admissions rate } \\
\text { ratio }(95 \% \mathrm{Cl})\end{array}$ & Number of ICU deaths (\%) & $\begin{array}{l}\text { Median length of stay } \\
\text { on ICU\# (IQR) }\end{array}$ \\
\hline \multicolumn{7}{|l|}{ Year } \\
\hline 2009 & 74 & 97,457 & $75.9(60.5-95.4)$ & 1.00 & $20(27.0)$ & $3.0(1.0-5.0)$ \\
\hline 2010 & 78 & 114,207 & $68.3(54.7-85.3)$ & $0.90(0.65-1.24)$ & $18(23.1)$ & $3.5(1.4-6.4)$ \\
\hline 2011 & 108 & 128,659 & $83.9(69.5-101.4)$ & $1.11(0.82-1.49)$ & $22(20.4)$ & $2.1(1.0-5.1)$ \\
\hline 2012 & 155 & 137,062 & $113.1(96.6-132.7)$ & $1.49(1.13-1.96)$ & $31(20.0)$ & $3.8(1.1-7.3)$ \\
\hline 2013 & 121 & 136,877 & $88.4(74.0-105.6)$ & $\begin{array}{l}1.16(0.87-1.55) \\
* p \text { for trend }=0.022\end{array}$ & $35(28.9)$ & $2.9(1.4-7.1)$ \\
\hline \multicolumn{7}{|l|}{ COPD } \\
\hline \multicolumn{7}{|l|}{ Year } \\
\hline 2009 & 3126 & 97,457 & $3204.6(3094.2-3318.9)$ & 1.00 & $642(20.5)$ & $3.2(1.4-7.9)$ \\
\hline 2010 & 3675 & 114,207 & $3217.8(3115.5-3223.6)$ & $1.01(0.96-1.05)$ & $717(19.5)$ & $3.0(1.4-6.7)$ \\
\hline 2011 & 3924 & 128,659 & $3049.9(2956.0-3146.9)$ & $0.95(0.91-1.00)$ & $718(18.3)$ & $2.9(1.3-6.3)$ \\
\hline 2012 & 4377 & 137,062 & $3193.4(3100.2-3289.5)$ & $0.99(0.95-1.04)$ & $818(18.7)$ & $3.0(1.4-6.4)$ \\
\hline \multirow[t]{2}{*}{2013} & 4652 & 136,877 & $3398.7(3302.4-3497.8)$ & $1.06(1.01-1.11)$ & $837(18.0)$ & $3.1(1.5-6.6)$ \\
\hline & & & & ${ }^{*} p$ for trend $=0.0003$ & & \\
\hline
\end{tabular}

*p value for likelihood ratio test. "length of stay in days.

bronchiectasis and 19,754 (3.2\%) from COPD. Bronchiectasis admissions increased from 74 in 2009 to 121 in 2013, equating to a crude annual increase of $8 \%$ (95\% Confidence Interval [CI] 2 to $15 \% ; \mathrm{p}=0.01$ ) (see Table 1 ). The mean age increased from 56.6 (standard deviation [SD] 18) to 65.8 years (SD 15.2; $\mathrm{p}=0.042)$ whilst ICU mortality did not change $(27.0 \%$ vs $28.9 \% ; \mathrm{p}=0.83)$. The unadjusted yearly increase in COPD admissions was $1 \%$ (95\% CI: $0.3 \%$ to $2 \% ; \mathrm{p}=0.012)$. The mean age in COPD patients remained static (67.5 years [SD 10.6] vs. 67.9 years [SD 10.6]; $\mathrm{p}=0.16)$, but ICU mortality decreased $(20.5 \%$ vs. $18.0 \%$; $=0.005)$. ICU mortality in people with bronchiectasis over $70(\mathrm{n}=219)$ was higher compared to those under $70(31.1 \%$ vs. $18.3 \%$; $<<0.001)$ despite having similar mean APACHE II acute physiology scores.

Conclusion Bronchiectasis admissions to ICU are increasing, and ICU mortality for is higher bronchiectasis compared to COPD, particularly in individuals above 70 years of age.

\section{P206 EXPERIENCE OF ESTABLISHING FUNDING FOR A HOME IV SERVICE FOR BRONCHIECTASIS}

A Booth, A McCleary, RA Thomas. York Hospitals NHS Trust, York, UK

\subsection{6/thoraxjn-2015-207770.342}

Background The benefit of intravenous (IV) antibiotics in bronchiectasis has been established, ${ }^{1}$ and IV antibiotics can be safely delivered in a domicillary setting. ${ }^{2}$ We report on the experience of obtaining funding through the CCG to establish a service delivering IV antibiotics safely and effectively to people with bronchiectasis at home.

Methods The model for home IV antibiotics involved a vascular surgeon placing a PICC line on day one under guided ultrasound, and an initial review by specialist nurse and physiotherapist. The specialist nurse administered the first dose. Education on line care, anaphylaxis and potential complications was provided. Drugs were delivered via a homecare company, Calea, and home IV doses were administered by specialist nurses from the homecare company. At the end of the course patients were reviewed by the specialist bronchiectasis nurse.
Results Negotiations with the CCG agreed funding for the service with $7.5 \mathrm{~h}$ of specialist nurse time and to meet the costs of the homecare company. Between July 2014 and July 20159 patients underwent 10 IV courses. A total of 132 days IV antibiotics were given, with 96 (73\%) being given at home. This saved bed days, at an estimated saving of $£ 26,400$. Seventy seven home visits were conducted by the homecare company specialist nurses at a cost of $£ 5625$ and the homecare drug cost was $£ 6134$ (total $£ 11,759$ or $£ 1,175$ per course). Overall cost savings amounted to approximately $£ 20,266$ for the ten courses, or $£ 2,026$ per course. One patient had to return to hospital for replacement of their line due to mechanical phlebitis, but was still able to complete the entire course. Qualitative feedback is being sought via patient questionnaires, and has proved very positive.

Conclusion Administering IV antibiotics at home for people with bronchiectasis is safe, reduces inpatient bed days and is cost effective.

\section{REFERENCES}

1 Murray MP, Turnbull K, Macquarrie S, Hill AT. Assessing response to treatment of exacerbations of bronchiectasis in adults. Eur Respir J. 2009;33:312-8

2 Bedi $\mathrm{P}$, Sidhu MK, Donaldson LS, et al. A prospective cohort study of the use of domicillary intravenous antibiotics in bronchiectasis. NPJ Prim Care Respir Med. 2014;24:14090

\section{P207 THORACIC INVOLVEMENT IN IGG4-RELATED DISEASE}

${ }^{1}$ RM Anstey, ${ }^{1} J P$ Corcoran, ${ }^{2} E L$ Culver, ${ }^{1}$ A Talwar, ${ }^{1}$ RJ Hallifax, ${ }^{1}$ I Psallidas, ${ }^{2} T N$ Cargill, ${ }^{2} \mathrm{CD}$ Manganis, ${ }^{2} \mathrm{E}$ Barnes, ${ }^{1} \mathrm{NM}$ Rahman. ${ }^{1}$ Oxford Centre for Respiratory Medicine, Oxford University Hospitals NHS Trust, Oxford, UK; ${ }^{2}$ Translational Gastroenterology Unit, Oxford University Hospitals NHS Trust, Oxford, UK

\subsection{6/thoraxjnl-2015-207770.343}

Background and objectives IgG4-related disease (IgG4-RD) is a multi-system fibro-inflammatory disorder originally described in association with autoimmune pancreatitis (AIP), usually but not always in the context of elevated serum IgG4 levels. Thoracic manifestations of IgG4-RD include mediastinal lymphadenopathy, lung nodules or masses, interstitial lung disease, bronchiectasis and pleural disease. 
The authors' regional IgG4-RD service is one of the largest UK-based units treating patients with this condition. Specialist clinics and multidisciplinary team meetings operate alongside an active research programme. We aimed to describe the frequency with which thoracic abnormalities - either as a symptomatic presenting feature of IgG4-RD or an incidental asymptomatic finding on imaging - were present in a prospectively recruited patient cohort.

Method and results Patients referred to the authors' IgG4-RD service from 2005 onwards and confirmed as having a diagnosis of IgG4-RD were included. Diagnoses were made using established clinical criteria (HISORt for AIP and Japanese International Consensus Diagnostic Criteria for systemic disease); tissue specimens were assessed using the Boston histopathological consensus criteria where available. Patients were followed prospectively; clinicopathological data relating to presentation and clinical progress were stored in a secure database with the consent of participants. In patients without symptomatic thoracic manifestations of IgG4-RD, routine clinical imaging (CXR and CT) was reviewed where available for evidence of incidental asymptomatic disease.

61 IgG4-RD patients with thoracic imaging available were included; mean age at diagnosis was 60.3 years (SD 14.6). 43 $(70.5 \%)$ patients were male. The majority of patients $(85.2 \%)$ presented with features of intra-abdominal disease. 6 patients (9.8\%) had evidence of symptomatic thoracic disease on the basis of clinical presentation, radiology and/or histology. A further $15(24.6 \%)$ patients had abnormal imaging suggestive of asymptomatic thoracic IgG4-RD.

Conclusion A significant proportion of IgG4-RD patients have evidence of symptomatic and asymptomatic thoracic manifestations of this multi-system disease. Respiratory physicians should consider IgG4-RD in their differential diagnosis for a range of pulmonary presentations, particularly where there is co-existing extra-thoracic organ involvement. Making a diagnosis of IgG4RD impacts on access to established therapeutic options including corticosteroids and rituximab to which the disease is responsive in the inflammatory phase.

\section{P208 PREVENTION OF VENTILATOR-ASSOCIATED PNEUMONIA WITH CHEST PHYSIOTHERAPY: A META-ANALYSIS}

GF Javelosa, RK De Borja, M Lagmay, K Villareal. University of the East Ramon Magsaysay Memorial Medical Center, Quezon City, Philippines

10.1136/thoraxjnl-2015-207770.344

Research question Among mechanically ventilated adult ICU patients, can chest physiotherapy (CPT) prevent the onset of ventilator-associated pneumonia (VAP) compared with standard care?

Introduction VAP is a common nosocomial infection with various known strategies for prevention, including CPT. Conflicting evidence regarding CPT for VAP prevention exist since CPT may cause desaturation and respiratory muscle fatigue.

Objectives To determine the efficacy of CPT, compared with standard care, in preventing the onset of VAP among mechanically ventilated adult ICU patients, its effect on ICU mortality, length of ICU stay, and duration of mechanical ventilation.

Inclusion criteria Controlled trials on adult mechanically ventilated ICU patients, given CPT for VAP prevention, compared with standard care.

Search strategy An electronic search in PubMed, EMBASE, CENTRAL, BioMedCentral, Elsevier Health, and Herdin was done. Reference lists were checked manually.

Study manoeuvres The authors arrived at a consensus and the Cochrane risk of bias tool was used for evaluation.

Statistical analysis Mantel-Haenszel method using the Review manager 5.3.

Results Twenty studies were found, and 10 were retrieved for review. Five studies were included, representing 595 patients. Evaluation of the included studies found 1 study with low risk of bias, 2 studies with high risk, and 2 studies with unclear risk. Overall combined meta-analysis of all 5 studies found no difference in VAP incidence between the 2 groups (RR 0.80, 95\% CI 0.52 to $1.23, \mathrm{P}=0.05)$. A subgroup analysis done excluding the studies with high risk of bias still showed no difference in VAP incidence ( $R R 0.96,95 \%$ CI 0.62 to $1.50, P=0.86$ ). CPT made no significant difference on ICU mortality (RR 0.97, 95\% CI 0.57 to $1.97, \mathrm{P}=0.07$ ), duration of ICU stay (RR 0.36, $95 \% \mathrm{CI}-1.83$ to $2.55, \mathrm{P}=0.10$ ), and duration of mechanical ventilation (RR $0.23,95 \% \mathrm{CI}-0.74$ to $1.21, \mathrm{P}=0.14$ ).

Conclusions It is not recommended to perform routine CPT on mechanically ventilated adult ICU patients to prevent the onset of VAP, as this is associated with potential harm and unnecessary costs. The authors recommend that more trials with low risk of bias be conducted on CPT for VAP prevention.

\section{P209 THE BURDEN OF HOSPITAL ACQUIRED PNEUMONIA: A COHORT STUDY}

${ }^{1} V$ Navaratnam, ${ }^{1} \mathrm{E}$ O'Dowd, ${ }^{2} \mathrm{H}$ Staniforth, ${ }^{3} \mathrm{~L}$ Haynes, ${ }^{2} \mathrm{~J}$ Lacey, ${ }^{4} \mathrm{~A}$ Gummow, ${ }^{1}$ RB Hubbard, ${ }^{5} \mathrm{~T}$ Bewick. ${ }^{1}$ Division of Epidemiology and Public Health, University of Nottingham, Nottingham, UK; ${ }^{2}$ Department of Pharmacy, Derby Teaching Hospitals NHS Foundation Trust, Derby, UK; ${ }^{3}$ Department of Clinical Coding, Derby Teaching Hospitals NHS Foundation Trust, Derby, UK; ${ }^{4}$ Department of Radiology, Derby Teaching Hospitals NHS Foundation Trust, Derby, UK; ${ }^{5}$ Department of Respiratory Medicine, Derby Teaching Hospitals Foundation Trust, Derby, UK

10.1136/thoraxjnl-2015-207770.345

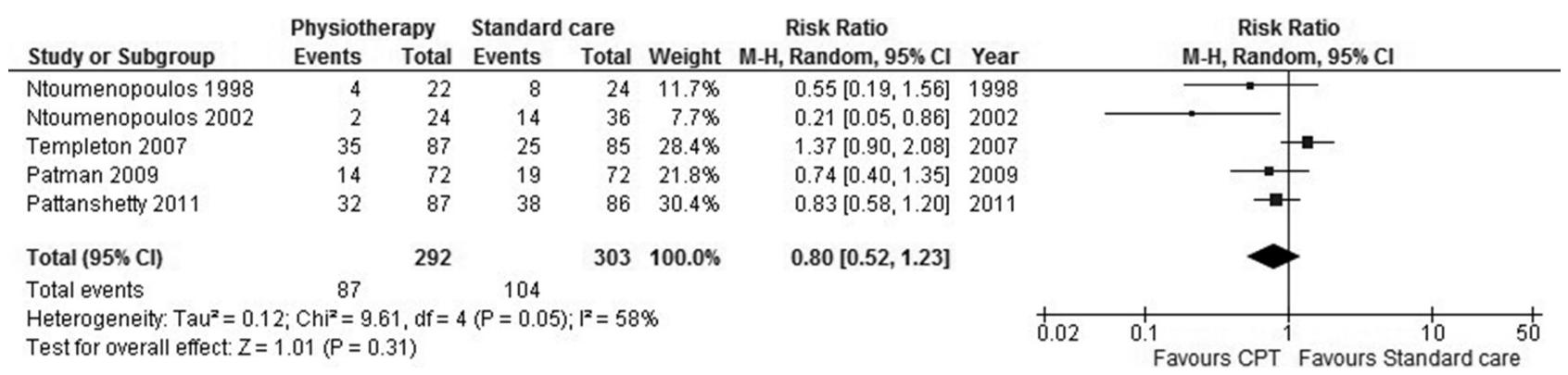

Abstract P208 Figure 1 